\title{
Effects of low-level laser therapy on the orthodontic mini-implants stability: a systematic review and meta-analysis
}

\author{
Ana Carolina de Figueiredo Costa $^{1^{*}}$ (D), Thays Allane Cordeiro Maia ${ }^{1}$ (D), Paulo Goberlânio de Barros Silva ${ }^{1}$, \\ Lucas Guimarães Abreu² (D), Delane Viana Gondim ${ }^{1,3}$ (i) and Pedro César Fernandes Santos ${ }^{1}$ (D)
}

\begin{abstract}
Objectives: The aim of this systematic review and meta-analysis was to assess the effects of low-level laser therapy (LLLT) on the orthodontic mini-implants (OMI) stability.

Materials and methods: An unrestricted electronic database search in PubMed, Science Direct, Embase, Scopus, Web of Science, Cochrane Library, LILACS, Google Scholar, and ClinicalTrials.gov and a hand search were performed up to December 2020. Randomized clinical trials (RCTs) or non-randomized clinical trials (Non-RCTs) that assessed the effects of LLLT on the OMI stability were included. Data regarding the general information, LLLT characteristics, and outcomes were extracted. The authors performed risk of bias assessment with Cochrane Collaboration's or ROBINS-I tool. Meta-analysis was also conducted.

Results: Five RCTs and one Non-RCT were included and 108 patients were evaluated. The LLLT characteristics presented different wavelength, power, energy density, irradiation time, and protocol duration. Five RCTs had a low risk of selection bias. Two RCTs had a low risk of performance and detection bias. All RCTs had a low risk of attrition bias, reporting bias and other bias. The Non-RCT presented a low risk of bias for all criteria, except for the bias in selection of participants. The meta-analysis revealed that LLLT significantly increased the OMI stability $(p<0.001$, Cohen's $d=0.67)$ and the highest clinical benefit was showed after $1(p<0.001$, Cohen's $d=0.75), 2(p<0.001$, Cohen's $d=1.21$ ), and 3 ( $p<0.001$, Cohen's $d=1.51$ ) months of OMl placement.
\end{abstract}

Conclusions: LLLT shows positive effects on the OMI stability.

Keywords: Orthodontic anchorage procedures, Mini-implants, Low-level laser therapy, Stability

\section{Introduction}

Orthodontic mini-implants (OMI) are the most effective tool for reinforcement of orthodontic anchorage [1]. This temporary anchorage device has become popular among orthodontists, being considered a versatile, welltolerated, low-invasive, simple to insert ad low-cost method. Moreover, OMI provides great mechanical predictability and stability [2].

\footnotetext{
* Correspondence: carolinafigueired@gmail.com

'Department of Clinical Dentistry, Faculty of Pharmacy, Dentistry and Nursing, Federal University of Ceará, Monsenhor Furtado Street, Rodolfo Teófilo, Fortaleza, Ceará 60430-350, Brazil

Full list of author information is available at the end of the article
}

The maintenance of mechanical stability and the absence of pain and peri-implant inflammation are directly related to the clinical success of the OMIs $[3,4]$. Primary stability is conferred shortly after the procedure for placement of the device and secondary stability is expressed after the healing phase. The retention of OMI in bone depends on numerous factors, such as bone density and thickness of the insertion site, device surface morphology, surgical technique, and physiological repair process $[3,5,6]$.

The low-level laser therapy (LLLT) is a non-invasive and painless method, consisting of the use of nonionizing light sources of the visible or infrared spectrum 
that acts under mitochondrial photoreceptors, increasing adenosine triphosphate production and cell proliferation [7]. Recent ex vivo and in vivo studies have demonstrated that the LLLT has promising effects in orthodontics, accelerating orthodontic movement, reducing orthodontic pain, and increasing the primary and secondary stability of OMIs [5, 8-11]. This last topic has great clinical interest, but there are still no systematic reviews aiming to elucidate the true effects of this therapy on skeletal anchorage.

Therefore, the present study aimed to perform a systematic review and meta-analysis of clinical trials assessing the effects of LLLT on the OMI stability.

\section{Material and methods}

\section{Protocol and registration}

This systematic review was submitted to the PROSPERO database (CRD42020188469). The reporting of this study is in accordance with the Preferred Reporting Items for Systematic Reviews and Meta-Analyses (PRISMA) statement and followed the guidelines in the Cochrane Handbook for Systematic Reviews of Interventions.

\section{Eligibility criteria}

The selection criteria were structured according to the PICOS (Patients, Intervention, Control, Outcome, Study design) strategy:

- Patients $(P)$. Individuals of both sexes, in permanent dentition, without restriction on ethnic or socioeconomic group, whose orthodontic treatment with fixed appliances required anchorage with OMI

- Intervention (I). Application of LLLT on OMI

- Control (C). Patients who received placebo or no treatment on OMI

- Outcome $(O)$. The primary outcome included the OMI stability. The secondary outcome could include pain, peri-implant inflammation, clinical success/failure range, or displacement of the OMI.

- Study design (S). Randomized clinical trials (RCTs) or non-randomized clinical trials (Non-RCTs)

Animal and laboratory studies, technical and case reports, and opinion and review articles were excluded.

\section{Information sources}

The main search was performed in the following electronic databases: PubMed, Science Direct, Embase, Scopus, Web of Science, Cochrane Library, and LILACS. Searches were conducted from databases' date of inception until December 2020. A combination of the Boolean operators $\mathrm{AND} / \mathrm{OR}$ and $\mathrm{MeSH} / \mathrm{non}-\mathrm{MeSH}$ terms was used to identify pertinent studies. The following search strategy was employed: orthodontic anchorage procedures OR mini-implants OR mini-screws OR microimplants OR skeletal anchorage OR temporary anchorage device OR bone screws AND lasers OR laser therapy OR low-level light therapy. Unpublished literature was searched in Google Scholar and ClinicalTrials.gov. The reference lists of all eligible studies were hand-searched to identify any additional relevant articles that might have been missed during the searches (Supplementary Material 1).

\section{Search strategy and study selection}

Two independent reviewers (ACFC and TACM) performed the study selection that comprised assessment of title, abstract, and full text of the retrieved references. No language or publication date restriction was imposed. After exclusion of duplicate and non-eligible studies, the full text of references considered eligible for inclusion were assessed by the two reviewers independently. Cases of disagreements were resolved by a third reviewer (PCFS). The Cohen $\kappa$ test was used to evaluate the level of agreement between reviewers (ACFC and TACM).

\section{Data collection process}

The two review authors (ACFC and TACM) extracted the relevant data of the included studies independently. A third reviewer (PCFS) resolved any discrepancies and questions.

Information from the included studies was synthesized by tabulating the general characteristics, including author, year of publication, country where the study was carried out, study design, number of participants along with information on their age and sex, number of OMI placed, site of placement and type of load, groups, evaluation methods, and follow-up. The specific information included the LLLT characteristics [laser device, wavelength, irradiation site, irradiation time/frequency, power (W), energy density $\left(\mathrm{J} / \mathrm{cm}^{2}\right)$, applications], the main findings and conclusions of the included studies.

\section{Risk of bias assessment}

The risk of bias of included randomized studies was assessment with the Cochrane Collaboration's Risk of Bias tool [12]. The criteria analyzed were (1) random sequence generation-selection bias, (2) allocation concealment-selection bias, (3) blinding of participants and personnel-performance bias, (4) blinding of outcome assessment-detection bias, (5) incomplete outcome data-attrition bias, (6) selective reporting-reporting bias, and (7) other bias. The risk of bias of included non-randomized studies was assessment with the Risk of Bias in Non-randomized Studies of Interventions (ROBINS-I) tool [13]. The criteria analyzed were (1) bias due to confounding, (2) bias in selection of participants 
into the study, (3) bias in measurement of interventions, (4) bias due to departures from intended interventions, (5) bias due to missing data, (6) bias in measurement of outcomes, (7) bias in selection of the reported result, and (8) overall.

Two review authors (ACFC and TACM) performed this qualitative synthesis independently and a third author (PCFS) resolved the discrepancies. The studies were classified in low, high, or unclear risk of bias.

\section{Meta-analysis}

To perform the meta-analysis, the means, standard deviation (SD), and sample size of the studies cited were extracted. Because they are different scales, a meta-analysis was performed by calculating the standardized means difference (SMD) and Cohen's $d$ estimate. As they are negative scales, the values obtained from the periotest value (PTV) had their sign inverted to adapt to the same standard of measurement of the positive scales-resonance frequency analysis (RFA) in Hertz or ISQ-value. Baseline measurements were considered, 3 days, 6-9 days, 12-15 days, 1 month (between 3 and 4 weeks), 2 months (between 6 and 8 weeks), and 3 months (between 10 and 12 weeks) after the OMI insertion. Inverse variance method with random effects was used for all meta-analysis. In both cases, a heterogeneity test and calculation of the $I^{2}$ coefficient were performed using the $\operatorname{RevMan}^{\oplus}$ software $(p<0.05)$.

\section{Results \\ Study selection}

A total of 943 references was identified in the initial search. After removing duplicates, 821 studies remained. Based on the PICOS strategy defined in this systematic review and met-analysis, 813 studies were excluded after assessment of titles and abstracts. The full texts of eight articles were retrieved and the eligibility was assessed. At the end of the study selection, six studies were included for the qualitative and quantitative synthesis $[5,6,10$, 14-16]. The level of agreement between reviewers was excellent $(\kappa=0.98$ for screening, $\kappa=0.85$ for eligibility, and $\kappa=1.0$ for included) (Fig. 1).

\section{Risk of bias assessment}

By Cochrane Collaboration's tool, five RCTs had a low risk of selection bias (random sequence generation and allocation concealment) $[5,10,14-16]$. In performance (blinding of participants and personnel) and detection bias (blinding of outcome assessor), two studies had a low risk $[10,14]$ and three had an unclear risk $[5,15$, 16]. All RCTs had a low risk of attrition bias (incomplete outcome data), reporting bias (selective reporting), and other bias [5, 10, 14-16] (Fig. 2). By ROBINS-I tool, the

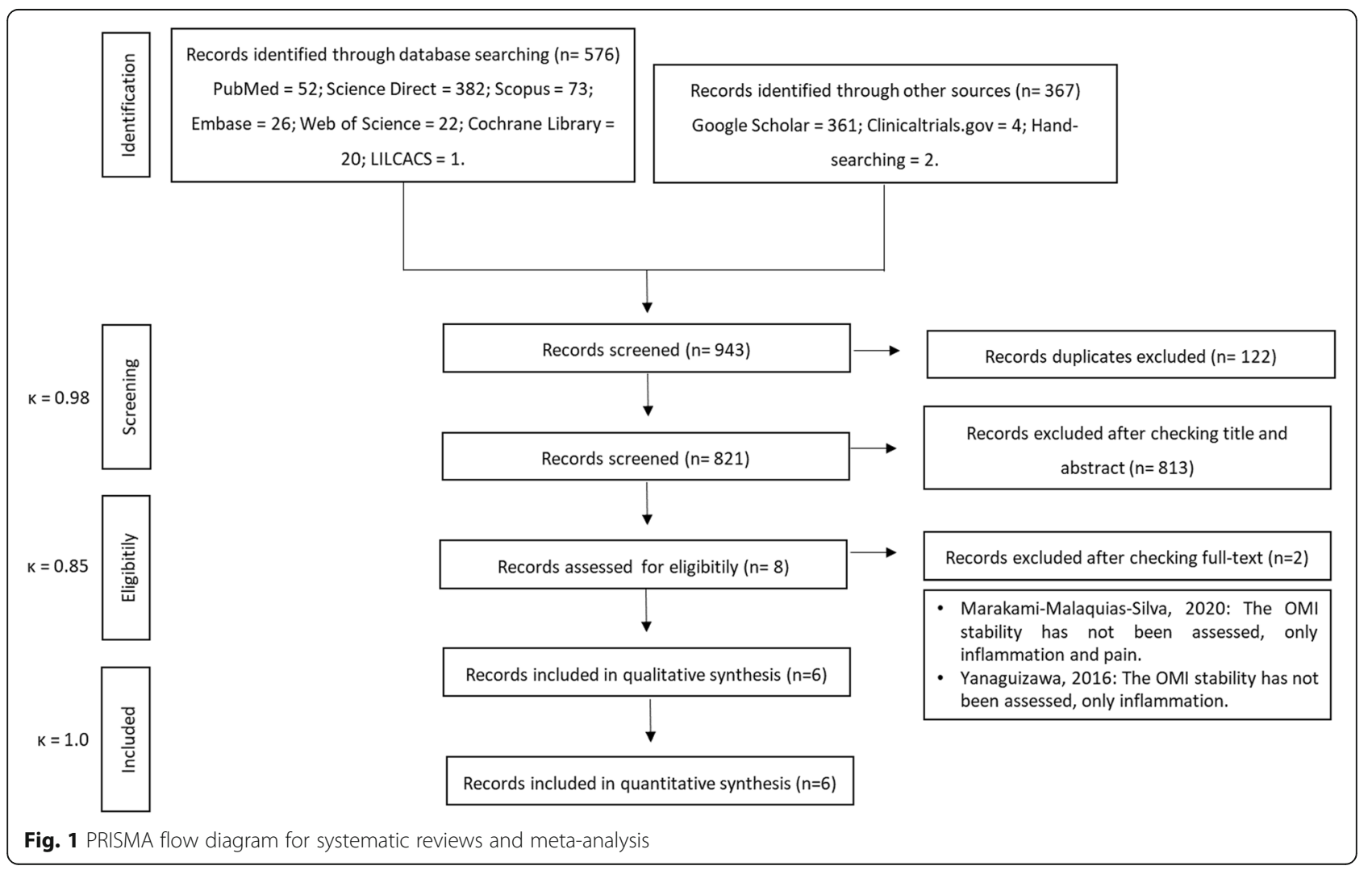




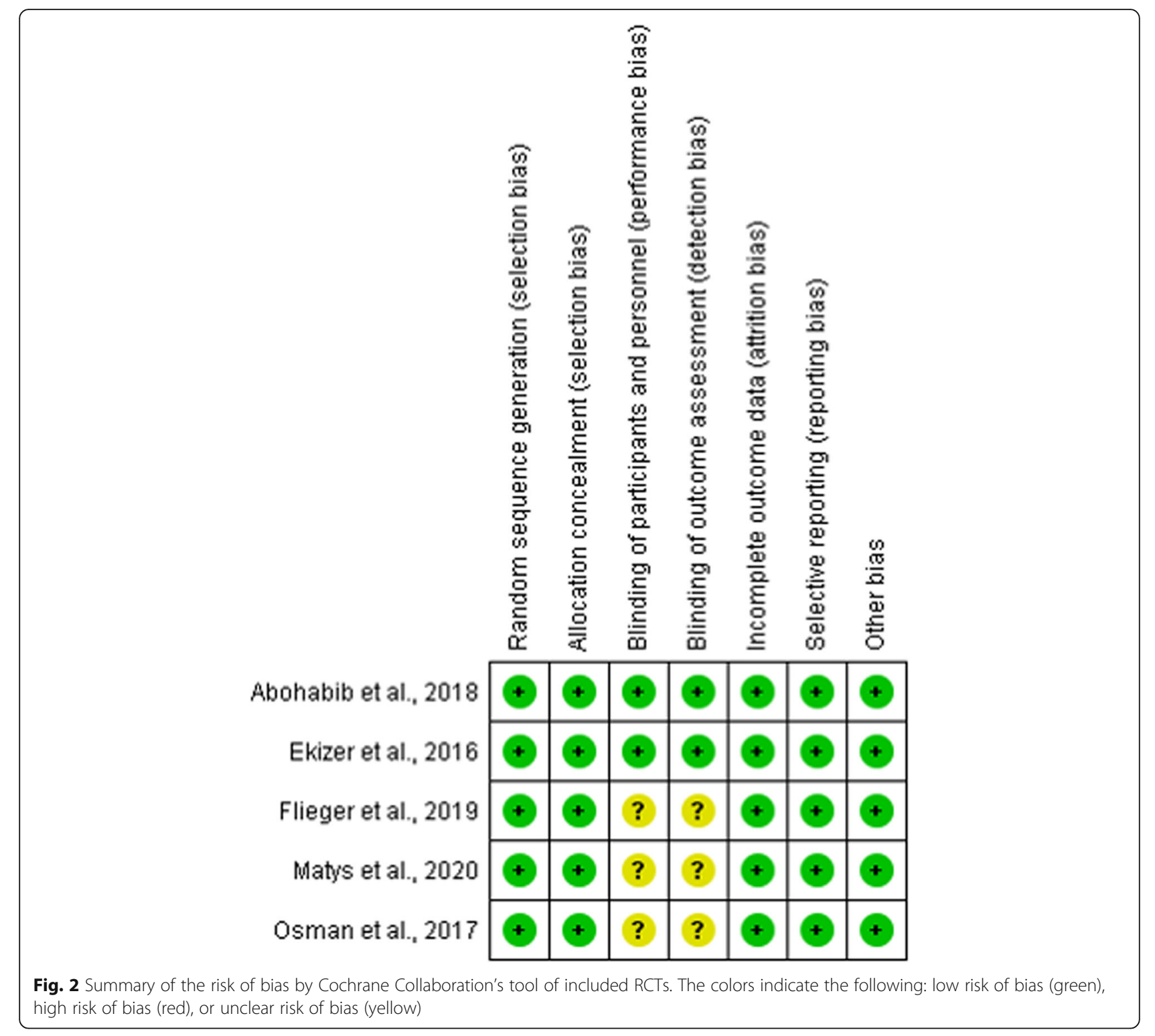

Non-RCT had a low risk of bias for all criteria evaluated, except for bias in selection of participants into the study [6] (Fig. 3).

Main findings of the systematic review and meta-analysis All eligible studies were clinical trials published in the past five years $[5,6,10,14-16]$. Five studies were RCTs $[5,10,14-16]$. Only one study was Non-RCT [6]. The studies were conducted in Egypt [10, 15], Turkey [14], Poland [5, 16], and Brazil [6], involving 108 patients of both sexes between 14 and 32.5 years [5, 6, 10, 14-16]. A total of $206 \mathrm{OMI}$, with diameter variation of 1.4 and $1.6 \mathrm{~mm}$ and length variation of 8 and $10 \mathrm{~mm}$, were exposed to LLLT or placebo [5, 6, 10, 14-16]. Maxilla was the site of placement of the OMIs in six studies $[5,6,10$, 14-16]. The mandible was also a site placement in only one study [6]. The load of $150 \mathrm{~g}$ was adopted in three studies $[6,10,15]$. One study evaluated immediate load [10], one study evaluated delay load [15], one study compared both [6], and in three studies, this information was unavailable $[5,14,16]$. All included articles evaluated the OMI stability through the PTV $[5,15,16]$ or RFA $[6,10,14]$. The $1 / 3$ evaluated pain $[5,16], 1 / 3$ evaluated local inflammation [14, 15], and $1 / 3$ evaluated parameters related to mobility were also assessed $[6,10]$. The follow-up ranged from 1 to 3 months $[5,6,10,14-$ 16] (Table 1).

Regarding the LLLT characteristics, the studies used the diode laser with wavelength varying from 618 to 940 $\mathrm{nm}$, power varying from 0.1 to $1.7 \mathrm{~W}$, and energy density varying from 4 to $36 \mathrm{~J} / \mathrm{cm}^{2}[5,6,10,14-16]$. The irradiation time per point varied from $20 \mathrm{~s}$ to $20 \mathrm{~min}$ and the 


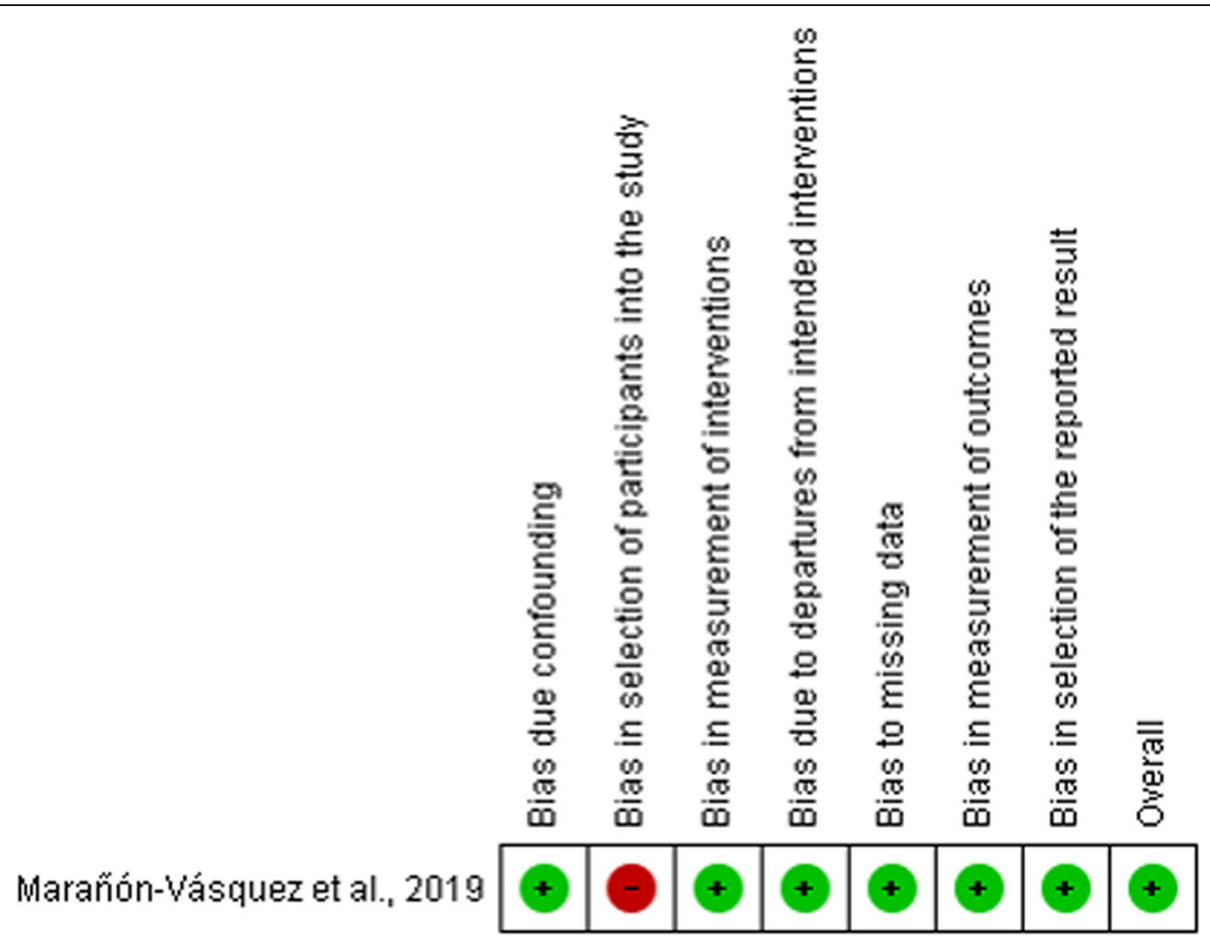

Fig. 3 Summary of the risk of bias by ROBBINS-I tool of included Non-RCT. The colors indicate the following: low risk of bias (green) and high risk of bias (red)

applications duration varied from 14 to 30 days $[5,6,10$, 14-16]. Four studies adopted irradiation at one point under the OMI insertion area $[6,10,14,15]$, and two studies irradiated at two points, by buccal and palatal areas of the maxillary ridge $[5,16]$ (Table 2).
Matys et al. and Flieger et al. observed that LLLT significantly increased the OMI stability, although there was no difference in pain experience $[5,16]$. Ekizer et al. also suggested that this therapeutic modality had positive effects on OMI stability, but there was no difference

Table 1 General characteristics of included studies

\begin{tabular}{|c|c|c|c|c|c|c|c|}
\hline Author, year & Country & $\begin{array}{l}\text { Study } \\
\text { design }\end{array}$ & $\begin{array}{l}\text { Participants } \\
\text { (sample; } \\
\text { gender; age) }\end{array}$ & $\begin{array}{l}\text { OMI (sample; dimensions; } \\
\text { site; load) }\end{array}$ & Groups & Evaluation methods & $\begin{array}{l}\text { Follow- } \\
\text { up time }\end{array}$ \\
\hline Abohabib, 2018 [10] & Egypt & $\mathrm{RCT}$ & $\begin{array}{l}15 \text { participants; - } \\
20.9 \pm 3.4 \text { years }\end{array}$ & $\begin{array}{l}30 \mathrm{OMl} ; 1.5 \mathrm{~mm} \text { diameter and } \\
8 \mathrm{~mm} \text { length; maxilla; IL (150 g) }\end{array}$ & L group; C group & $\begin{array}{l}\text { Stability: RFA using the Osstell } \\
\text { ISQ device. Clinical success/failure } \\
\text { rates: absence/presence of mobility. }\end{array}$ & 10 weeks \\
\hline Ekizer, 2016 [14] & Turkey & $\mathrm{RCT}$ & $\begin{array}{l}20 \text { participants; } \\
13 \mathrm{~F} / 7 \mathrm{M} ; 16.77 \\
\pm 1.41 \text { years }\end{array}$ & $\begin{array}{l}20 \mathrm{OMl} ; 1.6 \mathrm{~mm} \text { diameter and } \\
8 \mathrm{~mm} \text { length; maxilla; - }\end{array}$ & L group; C group & $\begin{array}{l}\text { Stability: RFA using the Osstell } \\
\text { ISQ device. Inflammation: } \\
\text { interleukin-1 } 1 \beta \text { levels in gingival } \\
\text { and peri-implant crevicular fluid }\end{array}$ & 3 months \\
\hline Flieger, 2019 & Poland & $\mathrm{RCT}$ & $\begin{array}{l}20 \text { participants; } \\
13 \mathrm{~F} / 7 \mathrm{M} ; 32.5 \\
\pm 6.1 \text { years }\end{array}$ & $\begin{array}{l}40 \mathrm{OMl} ; 1.4 \mathrm{~mm} \text { diameter and } \\
10 \mathrm{~mm} \text { length; maxilla; -. }\end{array}$ & L group; C group & $\begin{array}{l}\text { Stability: PTV using the Periotest } \\
\text { device. Pain: NRS-11 }\end{array}$ & 60 days \\
\hline $\begin{array}{l}\text { Marañón-Vásquez, } \\
2019 \text { [6] }\end{array}$ & Brazil & Non-RCT & 19 participants; -; - & $\begin{array}{l}48 \text { OMI for stability; } 35 \text { OMI for } \\
\text { displacement; } 1.5 \mathrm{~mm} \text { diameter } \\
\text { and } 8 \mathrm{~mm} \text { length; maxilla/ } \\
\text { mandible; IL/DL ( } 150 \mathrm{~g})\end{array}$ & $\begin{array}{l}\text { PBM + IL group; } \\
\text { PBM + DL group; } \\
\text { IL group/DL group }\end{array}$ & $\begin{array}{l}\text { Stability: RFA using the Osstell } \\
\text { ISQ device. Displacement: Images } \\
\text { from CBCT }\end{array}$ & 3 months \\
\hline Matys, 2020 [16] & Poland & $\mathrm{RCT}$ & $\begin{array}{l}22 \text { participants; } \\
14 \mathrm{~F} / 8 \mathrm{M} ; 31.7 \\
\pm 9.7 \text { years }\end{array}$ & $\begin{array}{l}44 \mathrm{OMl} ; 1.4 \mathrm{~mm} \text { diameter and } \\
10 \mathrm{~mm} \text { length; maxilla; - }\end{array}$ & L group; C group & $\begin{array}{l}\text { Stability: PTV using the Periotest } \\
\text { device. Pain: NRS-11 }\end{array}$ & 60 days \\
\hline Osman, 2017 [15] & Egypt & $\mathrm{RCT}$ & $\begin{array}{l}12 \text { participants; } \\
6 \mathrm{~F} / 6 \mathrm{M} ; 14 \text { to } \\
28 \text { years }\end{array}$ & $24 \mathrm{OMl}$; -; maxilla; DL (150 g) & L group; C group & $\begin{array}{l}\text { Stability: PTV using the Periotest } \\
\text { device. Inflammation: gingival } \\
\text { index }\end{array}$ & 60 days \\
\hline
\end{tabular}

$R C T$ randomized clinical trial, Non- $R C T$ non-randomized clinical trial, $F$ female sex, $M$ male sex, OMl orthodontic mini-implant, $L$ laser, $C$ control, $P B M$ photobiomodulation, $I L$ immediate loading, $D L$ delay loading, $P T V$ periotest value, NRS-11 numeric pain rating scale-11, RFA resonance frequency analysis, $C B C T$ cone beam computed tomograph 


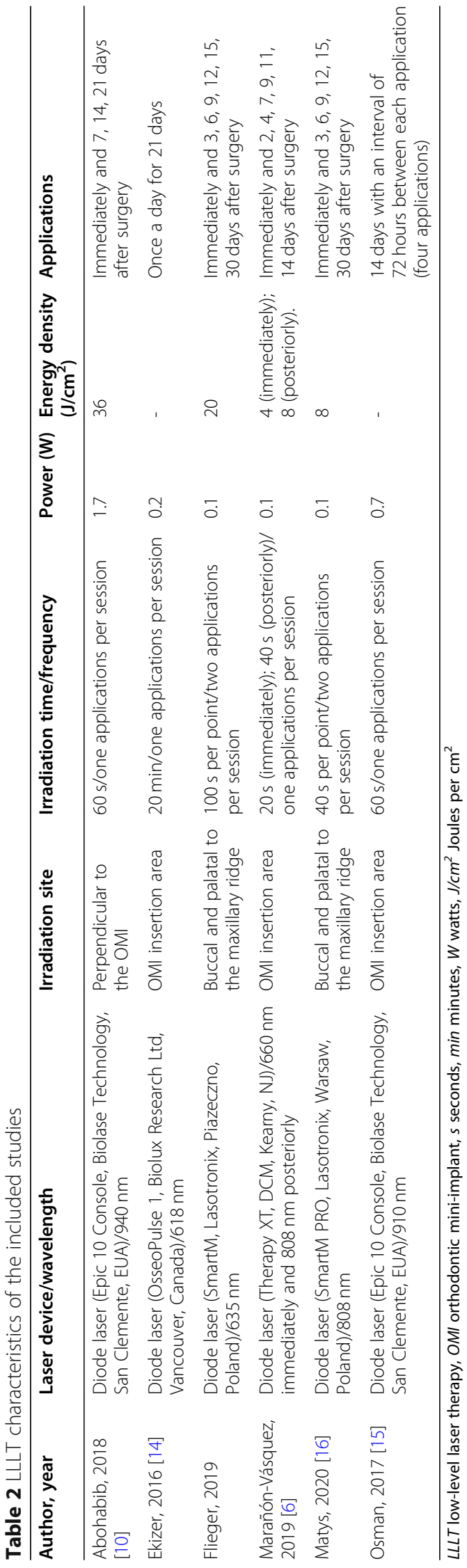


in the interleukin- $1 \beta$ levels in the gingival and periimplant crevicular fluid [14]. On the other hand, Osman et al. showed that LLLT improved the peri-implant inflammation but, despite improving OMI stability, there was no significant difference [15]. Marañón-Vásquez et al. found that the groups of individuals who received laser irradiation showed a reduction in the loss of the OMI stability and that the delay load increases this effect [6]. Only Abohabib et al. did not recommend the LLLT to promote the OMI stability during canine retraction [10]. This author found that, despite the LLLT reducing the RFA, there was no difference between the success/ failure rate between the intervention and control groups [10] (Table 3).

When the OMI stability data was evaluated, it was observed that, even with different scales, the LLLT significantly benefited this outcome $(p<0.001)$ with a Cohen's $d$ value of 0.67 (CI $95 \%=0.45$ to 0.89 ), a moderate effect estimate. However, due to the significant heterogeneity between/among studies $(p<0.001$, $I^{2}=74 \%$ ), subgroups analyses depending on the number of days or months after the LLLT were performed (Fig. 4).

Five studies performed the evaluation immediately after the OMI insertion and applying the LLLT or control $[5,10,14-16]$. There was no significant heterogeneity between/among studies $\left(p=0.910, I^{2}=0 \%\right)$ and there was no significant difference between groups ( $p=$ 0.250 ). The sensitivity analysis showed that the removal of studies from the meta-analysis did not significantly modify this outcome (Fig. 4).
The evaluation after 3 days was performed in Flieger et al. and Matys et al. including 42 LLLT patients and 41 control patients $[5,16]$. There was significant heterogeneity between the two studies $\left(p=0.020, I^{2}=81 \%\right)$ and treatment with LLLT showed a significant increase in the OMI stability compared to the control group ( $p=$ 0.030 ; Cohen's $d$ value $=1.19$ (CI 95\% $=0.09$ to 2.28$)$. The sensitivity analysis showed that the removal of data of Flieger et al. [5] ( $p=0.040)$ or Matys et al. [16] ( $p<$ 0.001) did not change this outcome (Fig. 4).

Between day 6 and day 9 period, four studies evaluating six outcomes showed that there was no significant difference between the LLLT or control in the OMI stability $(p=0.540)[5,10,15,16]$. There was no significant heterogeneity among the studies $\left(p=0.850, I^{2}=0 \%\right)$. The sensitivity analysis showed that the removal of individual studies did not significantly modify this outcome (Fig. 4).

Between day 12 and day 15, four studies evaluating six outcomes showed that there was no significant difference between the LLLT or control in the OMI stability $(p=0.270)[5,10,15,16]$. There was no significant heterogeneity among studies $\left(p=0.250, I^{2}=25 \%\right)$ and the sensitivity analysis showed that the individual removal of studies did not significantly modify this outcome (Fig. 4).

One month (between three to four weeks) after OMI placement, all the eligible studies, with a total of eight evaluation moments, showed that treatment with LLLT significantly improved the OMI stability $(p<0.001)$ with a Cohen's $d$ value of 0.75 (CI 95\% $=0.39$ to 1.11$)$

Table 3 Outcomes of included studies

\begin{tabular}{|c|c|c|}
\hline Author, year & Main findings & Conclusions \\
\hline Abohabib, 2018 [10] & $\begin{array}{l}\text { The overall success rate of the OMI was } 78.5 \% \text { for } L \text { and } C \text { groups. The } \\
\text { overall failed were three in each group, mainly observed within the first } 6 \\
\text { weeks. However, from } 3 \text { to } 10 \text { weeks, the } L \text { group showed significantly } \\
\text { increased mean RFA compared to C group. }\end{array}$ & $\begin{array}{l}\text { LLT cannot be recommended } \\
\text { as a clinically useful adjunct to } \\
\text { promoting OMl stability during } \\
\text { canine retraction. }\end{array}$ \\
\hline Ekizer, 2016 [14] & $\begin{array}{l}\text { OMl stability was significantly increased in the } L \text { group after } 2 \text { and } 3 \text { months. } \\
\text { There were no significant differences in the interleukin-1 } \beta \text { levels between the } \\
\text { groups. }\end{array}$ & $\begin{array}{l}\text { LLLT had a positive effect on } \\
\text { OMI stability. }\end{array}$ \\
\hline Flieger, 2019 & $\begin{array}{l}\text { L group showed higher secondary stability (lower mean PTV) in comparison } \\
\text { with C group after } 3,30 \text {, and } 60 \text { days. There was no significant difference in } \\
\text { the experience of pain between the groups. }\end{array}$ & $\begin{array}{l}\text { LLLT increased secondary OMI } \\
\text { stability. }\end{array}$ \\
\hline Marañón-Vásquez, 2019 [6] & $\begin{array}{l}\text { PBM groups presented lower loss of stability. DL groups presented lower loss } \\
\text { of stability, when the effective period of loading was assessed, independently } \\
\text { of the application of PBM. All groups showed displacement of the OMI } \\
\text { without significant differences. }\end{array}$ & $\begin{array}{l}\text { DL potentiated the effect of } \\
\text { PBM, decreasing the loss of } \\
\text { stability. }\end{array}$ \\
\hline Matys, 2020 [16] & $\begin{array}{l}\text { L group showed higher secondary stability (lower mean PTV) on } 30 \text { and } 60 \\
\text { days after starting treatment. There was no significant difference in the } \\
\text { experience of pain between the groups. }\end{array}$ & $\begin{array}{l}\text { LLLT increased secondary OMI } \\
\text { stability. }\end{array}$ \\
\hline Osman, 2017 [15] & $\begin{array}{l}\text { LLLT improved the stability of OMI, reducing PVT, but the results were not } \\
\text { statistically significant. LLLT reduced the gingival index values around OMI, } \\
\text { whereas the C group experienced moderate inflammation after } 2 \text { months of } \\
\text { placement. }\end{array}$ & $\begin{array}{l}\text { LLLT can be suggested as a } \\
\text { clinical adjuvant for improving } \\
\text { clinical success with OMI. }\end{array}$ \\
\hline
\end{tabular}




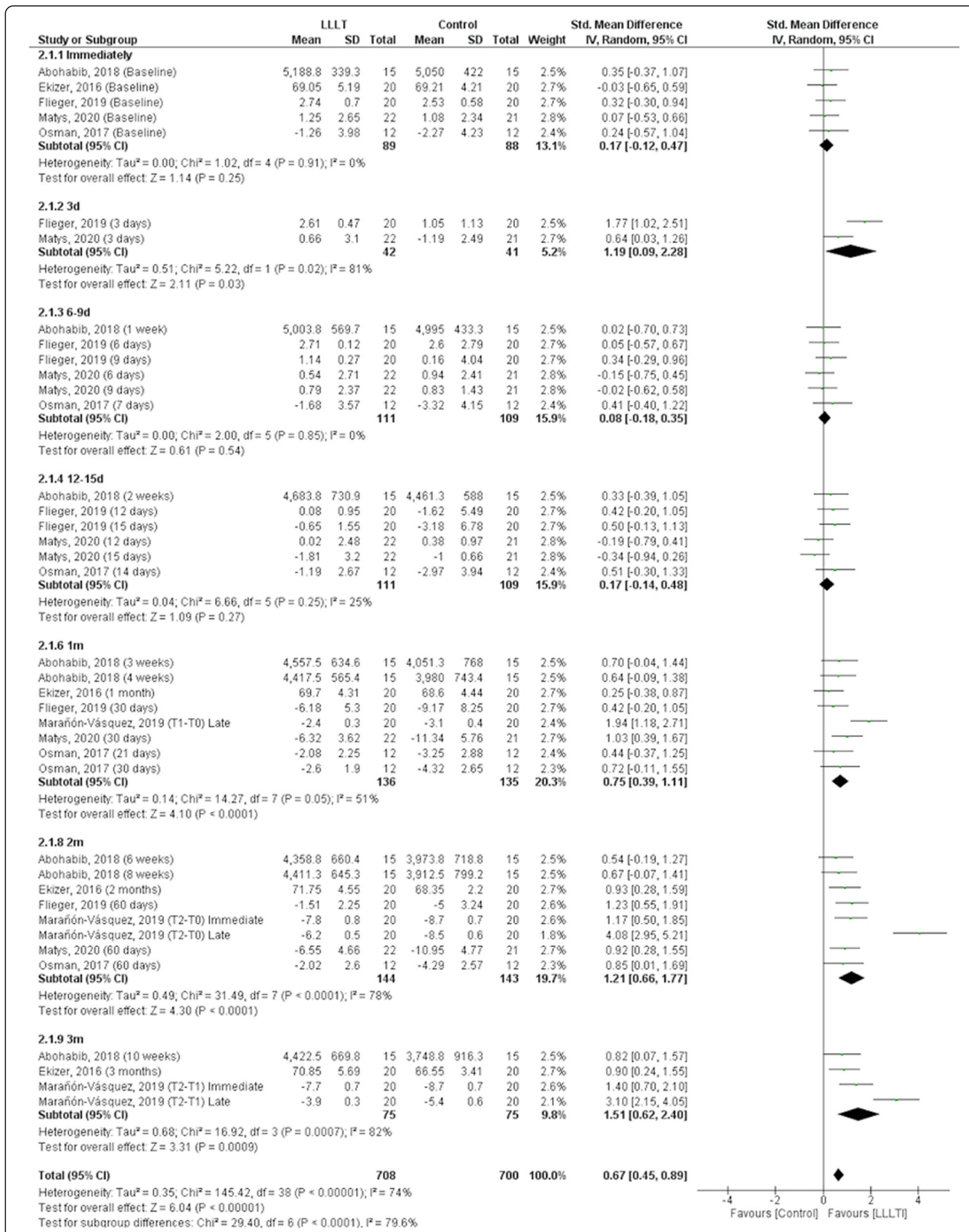

Fig. 4 Forest plot of the OMI stability according to the LLLT or control groups. Studies on the left and the right side of the middle line favor the control and the LLLT, respectively 
$[5,6,10,14-16]$. There was no significant heterogeneity among studies $\left(p=0.050, I^{2}=51 \%\right)$. The sensitivity analysis showed that the removal of individual studies did not significantly modify this outcome (Fig. 4).

Two months of evaluation (between six and eight weeks) after OMI placement, the six studies, with a total of eight evaluation moments, showed that the LLLT significantly improved the OMI stability $(p<0.001)$ with a Cohen's $d$ value of 1.21 (CI05\% $=0.66$ to 1.77$)$ [5, 6, 10, $14-16]$. There was significant heterogeneity among studies $\left(p<0.001, I^{2}=78 \%\right)$. The sensitivity analysis showed that the removal of individual studies did not significantly modify this outcome, except for the removal of data from Marañón-Vásquez et al. [6] (T2-T0), which significantly reduced heterogeneity ( $p=0.830, I^{2}=0 \%$ ) (Fig. 4).

Three months (between 10 and 12 weeks) after OMI placement, the three studies with a total of four evaluations showed that treatment with LLLT significantly improved the OMI stability $(p<0.001)$ with a Cohen's $d$ value of 1.51 (CI $95 \%=0.62$ to 2.40$)[6,10,14]$. There was significant heterogeneity among studies $(p<0.001$, $\left.I^{2}=82 \%\right)$. The sensitivity analysis showed that the removal of individual studies did not significantly modify this outcome, except for the removal of data from Marañón-Vásquez et al. [6] (T2-T1), which significantly reduced heterogeneity $\left(p=0.460, I^{2}=0 \%\right)$ (Fig. 4$)$.

\section{Discussion}

The quantity and quality of systematic reviews in Orthodontics have increased in recent years [17]. However, this is the first systematic review and meta-analysis to elucidate the effects of LLLT on OMI stability. It is also relevant to investigate secondary outcomes such as pain, peri-implant inflammation, clinical success/failure range, or displacement of the OMI, because they are related to stability.

The OMI stability can be assessed clinically by different methods, such as measuring insertion torque, resonance frequency analysis (RFA), and periotest value (PTV) [18]. The last two methods have greater sensitivity to measure the OMI stability and were used by the included articles of this systematic review and metaanalysis $[18,19]$.

Periotest was originally developed to measure the damping effect of the periodontal ligament around the teeth [20]. Posteriorly, it became useful to assess the mobility of implants and the primary stability of OMI [19, 21]. Percussion must be performed on the OMI head with a small pestle that will rebound at a specific speed depending on stability. During contact, a piezoelectric crystal inside the head of the pestle is deformed, thus creating an electric impulse that reveals the duration of contact, which is converted into stability expressed as PTV, ranging from -8 to +50 . A lower PTV often indicates better OMI stability. RFA is also a feasible measurement method for OMI stability [22, 23]. A SmartPeg with a permanent magnet is tightened into the implant or OMI. A handpiece emits electromagnetic impulses and a frequency in Hertz is recorded. Following computer-aided data analysis, resonance frequency in Hertz is converted into an "implant stability quotient" (ISQ) value, ranging from 0 to 100 . Higher ISQ values indicate better OMI stability $[24,25]$.

The clinical trials of this systematic review and metaanalysis demonstrated that the LLLT significantly benefited the OMI stability. Promising results regarding this effect has already been shown in animal models [7, 2628]. Experimental studies facilitate the understanding of biostimulatory mechanisms of photobiomodulation on bone regeneration and inflammation [26]. Garcez et al. demonstrated that a group of animals irradiated with LLLT showed less inflammatory infiltrate and better bone neoformation, with greater organization of collagen fibers, neovascularization, and epithelialization around the OMI. Omasa et al. observed that LLLT accelerated the peri-implant bone formation in rats and that a possible mechanism may be the stimulation of growth and transcription factors involved in the differentiation of osteoblasts, such as bone morphogenetic proteins-2. Goymen et al. and Pinto et al. evaluated the LLLT in rabbits and observed that this therapy increased the OMI stability via peri-implant bone formation. This systematic review and meta-analysis adds to knowledge because only clinical trials (RCTs and Non-RCT) were retrieved providing information with a higher level of scientific evidence.

As regards the secondary outcome of pain, although recent studies have shown that LLLT is effective in reducing pain intensity and duration after dental implant surgery, our study found no difference in pain after OMI placement with photobiomodulation [5, 14, 29]. However, bias might have taken place, as the fixed orthodontic appliance itself may cause the perception of pain reported by patients. In addition, AlSayed Hasan et al. found that the LLLT at intensities of 4 and $16 \mathrm{~J}$ did not generate a significant reduction in the levels of orthodontic pain caused by elastomeric separators [30].

Peri-implant inflammation was also assessed in this systematic review and meta-analysis because it is considered one of the main causes of OMI failure. Failures have occurred more frequently in the first weeks after OMI placement, probably because this trauma triggers a local inflammatory response, with an increase of proinflammatory cytokines that contribute to tissue destruction [5, 31]. During data extraction, we observed that two RCTs evaluated peri-implantitis. Osman et al. observed a significant reduction in the gingival index around the OMI in the laser group, corroborating literature findings that demonstrate a reduction in the levels 
of pro-inflammatory cytokines (IL-6 and IL-8) in the periimplant crevicular fluid of patients who had undergone LLLT [31]. On the other hand, Ekizer et al. did not observe significant changes in the levels of IL-1 $\beta$ between the laser and control groups. This cytokine is relevant in orthodontic movement, as it can enhance osteoclastic activity [32]. What may possibly contribute to this divergence of results in peri-implant inflammation is the difference of patients' oral hygiene practices [33].

In this systematic review and meta-analysis, only Abohabib et al. assessed clinical success and failure rate of OMI. This clinical trial observed that, despite the increase in the resonance frequency of OMI with laser therapy, the overall clinical success was $78.5 \%$ for the treated group and the control group, not suggesting a beneficial effect of LLLT. In contrast, a study that evaluated the effect of LLLT on the OMI success rate in animals, observed that in the laser group the success rate was $80 \%$ and higher than the control group, probably due to the anti-inflammatory and biostimulatory effects of this method [27].

The effects of LLLT are related to the treatment protocol, including wavelength, power, energy density, irradiation time, and frequency of treatment [34]. However, by a critical evaluation of the included articles, we did not observe homogeneous parameters in the LLLT protocols, impairing meaningful comparison of the results and demanding a skeptical look at the potential beneficial effects of this approach. This is justified by the fact that there are no univocal standardized guidelines for the use of photobiomodulation for osteoregenerative purposes [35]. However, the increased stability has been achieved in all clinical trials included in this systematic review and meta-analysis.

The wavelength of the LLLT should be highlighted. Two studies used the red laser (RL) $[5,14]$, three used the infrared laser (IRL) $[10,15,16]$, and one used both [6]. Long wavelengths, represented by IRL, penetrate deeper into the tissues, being more suitable to repair bone tissue. RL has more limited penetration power, being indicated to modulate inflammatory processes and stimulate soft tissue repair [36]. However, there is evidence that both can have beneficial effects on bone repair and on inflammatory process [37].

The present study has some limitations. First, only six studies were included. In addition, the LLLT characteristics, OMI dimensions, type of load, and evaluation methods were quite heterogeneous, making the comparison of study results limited. Although more high-quality RCTs with standardized LLLT protocols are highly encouraged, this study provides helpful information to the literature, as it is the first systematic review and metaanalysis of clinical trials assessing the effects of LLLT on OMI stability.

\section{Conclusions}

In general, LLLT has clinical applicability to increase OMI stability. However, due to the limitations of the current study, additional high-quality clinical trials are needed to elucidate the real effects of this therapy on OMI.

\section{Supplementary Information}

The online version contains supplementary material available at https://doi. org/10.1186/s40510-021-00350-y.

Additional file 1. Electronic search strategy.

\section{Abbreviations}

LLLT: Low-level laser therapy; OMl: Orthodontic mini-implants; RCT: Randomized clinical trials; Non-RCT: Non-randomized clinical trials; PRIS MA: Preferred Reporting Items for Systematic Reviews and Meta-Analyses; PICOS: Patients, Intervention, Control, Outcome, Study design; ROBINS-I: Risk of Bias in Non-randomized Studies of Interventions; SD: Standard deviation; SMD: Standardized means difference; PVT: Periotest value; RFA: Resonance frequency analysis

Acknowledgements

Not applicable.

\section{Authors' contributions}

ACFC performed the concept and design of the study, search strategy, data extraction and qualitative synthesis, and wrote the manuscript. TACM performed search strategy, data extraction, and qualitative synthesis. PGBS performed the quantitative synthesis. LGA, DVG, and PCFS guided the study and critically reviewed the manuscript. The author(s) read and approved the final manuscript.

\section{Funding}

This research did not receive any specific grant from funding agencies.

Availability of data and materials

The datasets used and/or analyzed during the current study are available from the corresponding author on reasonable request.

Ethics approval and consent to participate

Not applicable.

Consent for publication

Not applicable.

Competing interests

The authors declare no competing interests.

\section{Author details}

${ }^{1}$ Department of Clinical Dentistry, Faculty of Pharmacy, Dentistry and Nursing, Federal University of Ceará, Monsenhor Furtado Street, Rodolfo Teófilo, Fortaleza, Ceará 60430-350, Brazil. ²Department of Paediatric Dentistry and Orthodontics, Faculty of Dentistry, Federal University of Minas Gerais, Belo Horizonte, Minas Gerais, Brazil. ${ }^{3}$ Department of Morphology, Faculty of Medicine, Federal University of Ceará, Fortaleza, Ceará, Brazil.

Received: 19 November 2020 Accepted: 28 January 2021

Published online: 15 February 2021

\section{References}

1. Zheng $X$, Sun Y, Zhang Y, Cai T, Sun F, Li J. Implants for orthodontic anchorage: an overview. Medicine. 2018;97:232. https://doi.org/10.1097/MD. 0000000000010232

2. $X u$ Y,$X i e ~ J . C o m p a r i s o n$ of the effects of mini-implant and traditional anchorage on patients with maxillary dentoalveolar protrusion. Angle Orthod. 2017;87:320-7. https://doi.org/10.2319/051016-375.1. 
3. Leo M, Cerroni L, Pasquantonio G, Condò SG, Condò R. Temporary anchorage devices (TADs) in orthodontics: review of the factors that influence the clinical success rate of the mini-implants. Clin Ter. 2016;167: 70-7. https://doi.org/10.7417/CT.2016.1936.

4. Gurdán Z, Szalma J. Evaluation of the success and complication rates of selfdrilling orthodontic mini-implants. Niger J Clin Pract. 2018;21:546-56. https://doi.org/10.4103/njcp.njcp_105_17.

5. Flieger R, Gedrange T, Grzech-Leśniak K, Dominiak M, Matys J. Low-level laser therapy with a $635 \mathrm{~nm}$ diode laser affects orthodontic mini-implants stability: a randomized clinical split-mouth trial. J Clin Med. 2020;9:112.

6. Marañón-Vásquez GA, Lagravère MO, Borsatto MC, de Souza SS, Watanabe PC, Matsumoto MA, Romano FL. Effect of photobiomodulation on the stability and displacement of orthodontic mini-implants submitted to immediate and delayed loading: a clinical study. Lasers Med Sci. 2019;34: 1705-15. https://doi.org/10.1007/s10103-019-02818-0.

7. Pinto MR, dos Santos RL, Pithon MM, de Souza Araújo MT, Braga JPV, Nojima LI. Influence of low-intensity laser therapy on the stability of orthodontic miniimplants: a study in rabbits. Oral Surg Oral Med Oral Pathol Oral Radiol. 2013; 115:26-30. https://doi.org/10.1016/j.000o.2011.09.036.

8. AISayed Hasan MMA, Sultan K, Hamadah O. Low-level laser therapy effectiveness in accelerating orthodontic tooth movement: a randomized controlled clinical trial. Angle Orthod. 2017;87:499-504. https://doi.org/1 0.2319/062716-503.1.

9. Deana NF, Zaror C, Sandoval P, Alves N. Effectiveness of low-level laser therapy in reducing orthodontic pain: a systematic review and metaanalysis. Pain Res Manag. 2017;2017:2017. https://doi.org/10.1155/2017/ 8560652.

10. Abohabib AM, Fayed MM, Labib AH. Effects of low-intensity laser therapy on the stability of orthodontic mini-implants: a randomised controlled clinical trial. J Orthod. 2018:45:149-56. https://doi.org/10.1155/2017/8560652.

11. Demirsoy KK, Kurt G. Use of laser systems in orthodontics. Turk J Orthod. 2020:33:133-40. https://doi.org/10.5152/TurkJOrthod.2020.18099.

12. Higgins JP, Altman DG, Gotzsche PC, Cochrane Bias Methods Group, Cochrane Statistical Methods Group, et al. The Cochrane Collaboration's tool for assessing risk of bias in randomized trials. BMJ. 2011;343:d5928. https:// doi.org/10.1136/bmj.d5928.

13. Sterne JAC, Hernán MA, Reeves BC, et al. ROBINS-I: a tool for assessing risk of bias in non-randomised studies of interventions. BMJ. 2016;355:i4919. https://doi.org/10.1136/bmj.i4919.

14. Ekizer A, Türker G, Uysal T, Güray E, Taşdemir Z. Light emitting diode mediated photobiomodulation therapy improves orthodontic tooth movement and miniscrew stability: a randomized controlled clinical trial. Lasers Surg Med. 2016;48:936-43. https://doi.org/10.1002/lsm.22516.

15. Osman A, Moneim AA, El Harouni N, Shokry M. Long-term evaluation of the effect of low-level laser therapy on orthodontic miniscrew stability and periimplant gingival condition: a randomized clinical trial. J World Fed Orthod. 2017;6:109-14. https://doi.org/10.1016/j.ejwf.2017.08.005.

16. Matys J, Flieger R, Gedrange T, Janowicz K, Kempisty B, Grzech-Leśniak K, Dominiak M. Effect of $808 \mathrm{~nm}$ semiconductor laser on the stability of orthodontic micro-implants: a split-mouth study. Materials. 2020;13:2265. https://doi.org/10.3390/ma13102265.

17. Vásquez-Cárdenas J, Zapata-Noreña Ó, Carvajal-Flórez Á, Barbosa-Liz DM Giannakopoulos NN, Faggion CM Jr. Systematic reviews in orthodontics: impact of the PRISMA for Abstracts checklist on completeness of reporting Am J Orthod Dentofacial Orthop. 2019;156:442-52. https://doi.org/10.1016/ j.ajodo.2019.05.009

18. Nienkemper M, Santel N, Hönscheid R, Drescher D. Orthodontic miniimplant stability at different insertion depths. J Orofac Orthop. 2016;77:296303. https://doi.org/10.1007/s00056-016-0036-2.

19. Watanabe T, Miyazawa K, Fujiwara T, Kawaguchi M, Tabuchi M, Goto S Insertion torque and Periotest values are important factors predicting outcome after orthodontic miniscrew placement. Am J Orthod Dentofacial Orthop. 2017;152:483-8. https://doi.org/10.1016/j.ajodo.2017.01.026.

20. Schulte W, Lukas D. The Periotest method. Int Dental J. 1992:42:433-40.

21. Bilhan $\mathrm{H}$, Cilingir A, Bural C, Bilmenoglu C, Sakar O, Geckili O. The evaluation of the reliability of Periotest for implant stability measurements: an in vitro study. J Oral Implantol. 2015;41:90-5. https://doi.org/10.1563/aaid-joi-D-1300303.

22. Nienkemper M, Wilmes B, Panayotidis A, Pauls A, Golubovic V, Schwarz F, Drescher D. Measurement of mini-implant stability using resonance frequency analysis. Angle Orthod. 2013;83:230-8. https://doi.org/10.2319/043 012-354.1.

23. Tseng YC, Pan CY, Liu PH, Yang YH, Chang HP, Chen CM. Resonance frequency analysis of miniscrew implant stability. J Oral Sci. 2018;60:64-9. https://doi.org/10.2334/josnusd.16-0613.

24. Chen MHM, Lyon K, Tawse-Smith A, Ma S. Resonance frequency analysis in assessing implant stability: a retrospective analysis. Int J Prosthodont. 2019; 32:317-26. https://doi.org/10.11607/ijp.6057.

25. Khouja N, Tai WC, Shen IY, Sorensen JA. A critique of resonance frequency analysis and a novel method for quantifying dental implant stability in vitro. Int J Oral Maxillofac Implants. 2019;34:595-603. https://doi.org/10.11607/ jomi.7173.

26. Omasa S, Motoyoshi M, Arai Y, Ejima Kl, Shimizu N. Low-level laser therapy enhances the stability of orthodontic mini-implants via bone formation related to BMP-2 expression in a rat model. Photomed Laser Surg. 2012;30: 255-61. https://doi.org/10.1089/pho.2011.3157.

27. Garcez AS, Suzuki SS, Martinez EF, lemini MG, Suzuki H. Effects of lowintensity laser therapy over mini-implants success rate in pigs. Lasers Med Sci. 2015;30:727-32. https://doi.org/10.1007/s10103-013-1367-5.

28. Goymen M, Isman E, Taner L, Kurkcu M. Histomorphometric evaluation of the effects of various diode lasers and force levels on orthodontic mini screw stability. Photomed Laser Surg. 2015;33:29-34. https://doi.org/10.1 089/pho.2014.3833.

29. Caccianiga G, Perillo L, Portelli M, Baldoni M, Galletti C, Gay-Escoda C. Evaluation of effectiveness of photobiostimulation in alleviating side effects after dental implant surgery. A randomized clinical trial. Med Oral Patol Oral Cir Bucal. 2020;25:277-82. https://doi.org/10.4317/medoral.23336.

30. AlSayed Hasan MMA, Sultan K, Hamadah O. Evaluating low-level laser therapy effect on reducing orthodontic pain using two laser energy values: a split-mouth randomized placebo-controlled trial. Eur J Orthod. 2018;40:238. https://doi.org/10.1093/ejo/cjx013.

31. Yanaguizawa MS, Suzuki SS, Martinez EF, Suzuki H, Pelegrin MCJ, Garcez AS. Effects of low-level laser therapy in orthodontic patients on immediate inflammatory response after mini-implants insertion: a preliminary report. Photomed Laser Surg. 2017;35:57-63. https://doi.org/10.1089/pho.2015.3959.

32. Jose JA, Somaiah S, Muddaiah S, Shetty B, Reddy G, Roopa S. A comparative evaluation of interleukin 1 beta and prostaglandin E2 with and without low-level laser therapy during En masse retraction. Contemp Clin Dent. 2018;9:267-75. https://doi.org/10.4103/ccd.ccd_859_17.

33. Park HS, Jeong SH, Kwon OW. Factors affecting the clinical success of screw implants used as orthodontic anchorage. Am J Orthod Dentofacial Orthop. 2006;130:18-25. https://doi.org/10.1016/j.ajodo.2004.11.032.

34. Vanin AA, Verhagen E, Barboza SD, Costa LOP, Leal-Junior ECP. Photobiomodulation therapy for the improvement of muscular performance and reduction of muscular fatigue associated with exercise in healthy people: a systematic review and meta-analysis. Lasers Med Sci. 2017 33:1-34. https://doi.org/10.1007/s10103-017-2368-6.

35. Tani A, Chellini F, Giannelli M, Nosi D, Zecchi-Orlandini S, Sassoli C. Red (635 $\mathrm{nm})$, near-infrared $(808 \mathrm{~nm})$ and violet-blue $(405 \mathrm{~nm})$ photobiomodulation potentiality on human osteoblasts and mesenchymal stromal cells: a morphological and molecular in vitro study. Int J Mol Sci. 2018;19:1946. https://doi.org/10.3390/ijms19071946.

36. Pinheiro ALB. Advances and perspectives on tissue repair and healing. Photomed Laser Surg. 2009;27:833-6. https://doi.org/10.1089/pho.2009.2716.

37. Pagin MT, de Oliveira FA, Oliveira RC, Sant'Ana ACP, de Rezende MLR, Greghi SLA, Damante CA. Laser and light-emitting diode effects on preosteoblast growth and differentiation. Lasers Med Sci. 2012;29:55-9. https://doi.org/10.1007/s10103-012-1238-5.

\section{Publisher's Note}

Springer Nature remains neutral with regard to jurisdictional claims in published maps and institutional affiliations. 